Acta Veterinaria Hungarica 62 (1), pp. 106-116 (2014)

DOI: $10.1556 /$ AVet 2013.046

First published online 11 December 2013

\title{
EFFECTS OF SKIM-MILK SUPPLEMENTATION ON THE QUALITY AND PENETRATING ABILITY OF BOAR SEMEN AFTER LONG-TERM PRESERVATION AT $15^{\circ} \mathrm{C}$
}

\author{
Zhao NAmula, Risa Kodama, Fuminori TaniHara, Yasuhiro Morita, Yoko SATo, \\ Manita WiTTAYARAT, Masayasu TANIGUCHI and Takeshige OTOI ${ }^{*}$ \\ The United Graduate School of Veterinary Science, Yamaguchi University, \\ Yamaguchi 753-8515, Japan
}

(Received 30 August 2010; accepted 11 December 2012)

\begin{abstract}
This study investigated the effects of skim-milk supplementation on the quality and penetrating ability of boar semen preserved at $15^{\circ} \mathrm{C}$. When boar semen samples were preserved in Modified Modena extender supplemented with various concentrations $(0,7.5,15,30$ and $50 \mathrm{mg} / \mathrm{mL})$ of skim milk powder at $15{ }^{\circ} \mathrm{C}$ for 4 weeks, higher sperm motility and viability were observed in the case of $7.5 \mathrm{mg} / \mathrm{mL}$ skim-milk supplementation compared with the control group $(0 \mathrm{mg} / \mathrm{mL})$ during the preservation $(\mathrm{P}<0.05)$. When in vitro matured oocytes were co-incubated with boar sperm that had been preserved in Modified Modena extender with three different concentrations $(0,7.5$ or $15 \mathrm{mg} / \mathrm{mL})$ of skim milk powder at $15{ }^{\circ} \mathrm{C}$ for two weeks, there were no apparent effects of skim-milk supplementation on the rates of fertilisation and development to blastocysts of oocytes after co-incubation. However, the monospermic fertilisation rate of sperm preserved with $15 \mathrm{mg} / \mathrm{mL}$ skim milk powder was higher $(\mathrm{P}<0.05)$ than that of fresh non-preserved sperm, but did not differ among the preservation groups. The results indicate that the supplementation of Modified Modena extender with $7.5 \mathrm{mg} / \mathrm{mL}$ skim milk powder improves the motility and viability, but not the penetrating ability, of sperm after liquid preservation for at least two weeks.
\end{abstract}

Key words: Antioxidant, in vitro fertilisation, reactive oxygen species, sperm quality

The application of artificial insemination (AI) in swine breeding has increased dramatically worldwide due to the use of extended semen preserved at 15-18 ${ }^{\circ} \mathrm{C}$ for several days (Johnson et al., 2000). The quality of preserved semen is affected by handling procedures such as dilution, centrifugation and cooling, which are associated with the generation and imbalance of reactive oxygen species (ROS) (Bustamante Filho et al., 2009). Normally, the level of ROS is well controlled by self-antioxidants in cell metabolism (Agarwal et al., 2003). How-

*Corresponding author; E-mail: otoi@yamaguchi-u.ac.jp; Phone/Fax: 0081 (83) 933-5904 
ever, when an imbalance between excessive production and accumulation of ROS and antioxidant defence mechanisms (oxidative stress) occurs, it leads to sperm damage and reduced semen quality, resulting in decreased sperm motility, capacity for sperm-oocyte fusion, and fertility (Michael et al., 2008). Enzymatic (superoxide dismutase, catalase and glutathione peroxidase) and non-enzymatic (e.g. ascorbic acid, $\alpha$-tocopherol, taurine and albumin) antioxidant systems are effective defence mechanisms of sperm and seminal plasma against the toxic effects of oxidative stress (Griveau et al., 1995; Michael et al., 2008; Bustamante Filho et al., 2009).

In stallion and goat semen, skim milk provides non-enzymatic antioxidant factors that compensate for the loss resulting from seminal plasma removal (Bustamante Filho et al., 2009). Moreover, skim milk has been used instead of seminal plasma for thawing deep-frozen boar semen (Einarsson et al., 1972). Non-enzymatic antioxidant defences constitute a large number of molecules, including amino acids, peptides, proteins and vitamins, that have different reaction centres (e.g. phenols and thiols) with widely different hydrophobicities that allow the trapping of both hydrophobic and hydrophilic radicals (Evelson et al., 2001). Moreover, skim milk protects domestic animal sperm against cold-shock damage (Pagl et al., 2006).

The aim of this study was to determine the effects of skim-milk supplementation for long-term storage of boar semen preserved in Modified Modena extender at $15{ }^{\circ} \mathrm{C}$ by the assessment of sperm quality (motility, viability, plasma membrane integrity and acrosomal integrity) and in vitro fertilisation.

\section{Materials and methods}

\section{Semen collection and preparation}

Semen was collected from three fertile boars (Large White), aged 1.5 years, by using the 'gloved-hand' technique. Semen samples were diluted threefold with Modified Modena extender, then transported at $30^{\circ} \mathrm{C}$ to the laboratory within $2 \mathrm{~h}$ of collection. Modified Modena extender consisted of $27.5 \mathrm{mg} / \mathrm{mL}$ D-fructose (Sigma-Aldrich, St. Louis, MO, USA), $6.9 \mathrm{mg} / \mathrm{mL}$ trisodium citrate dehydrate (Wako Pure Chemical Industries, Osaka, Japan), $2.35 \mathrm{mg} / \mathrm{mL}$ ethylenediaminetetraacetic acid disodium salt (Wako Pure Chemical Industries), $1.0 \mathrm{mg} / \mathrm{mL}$ sodium hydrogen carbonate (Wako Pure Chemical Industries), $2.9 \mathrm{mg} / \mathrm{mL}$ citric acid monohydrate (Wako Pure Chemical Industries), $5.65 \mathrm{mg} / \mathrm{mL}$ Tris (hydroxymethyl) aminomethane (Sigma-Aldrich) and $0.2 \mathrm{mg} / \mathrm{mL}$ amikacin sulphate (Meiji, Tokyo, Japan) in distilled water. The diluted semen was centrifuged at $550 \times \mathrm{g}$ for $2 \mathrm{~min}$. After removal of supernatant, the pellets were pooled into one tube and then diluted in Modified Modena extender to a final concentration of $3 \times 10^{8}$ cells $/ \mathrm{mL}$. The extended semen samples were further diluted in Modified Modena extender 
with or without skim milk (Snow Brand Products Company, Sapporo, Japan) supplementation to give a final concentration of $1 \times 10^{8}$ cells $/ \mathrm{mL}$. The extended semen samples were then preserved in $15 \mathrm{~mL}$ conical polystyrene tubes. To reduce the effects of cold shock on the sperm during the chilling process, the tubes were placed in a 500-mL glass beaker containing $350-400 \mathrm{~mL}$ water at $30^{\circ} \mathrm{C}$ for $2 \mathrm{~min}$, then cooled in a refrigerator at $15^{\circ} \mathrm{C}$ and preserved for two or four weeks. An aliquot of each sample was used for analyses of sperm characteristics before preservation and once a week as described below.

\section{Sperm quality assessments}

Diluted semen in Modified Modena extender supplemented with 0, 7.5, 15,30 or $50 \mathrm{mg} / \mathrm{mL}$ of skim milk powder was stored at $15{ }^{\circ} \mathrm{C}$ for 4 weeks. The sperm quality (motility, viability, plasma membrane integrity, and acrosomal integrity) was periodically assessed as described below for up to 4 weeks after semen collection.

A $300-\mu \mathrm{L}$ aliquot of each chilled semen sample was taken on each experimental day. The sample was mixed by pipetting and warmed at $37^{\circ} \mathrm{C}$ for $10 \mathrm{~min}$ before evaluation. Each sample was diluted 10-fold with Modified Modena extender and placed in a warm glass chamber for assessment of motility. Briefly, a portion (approximately $10 \mu \mathrm{L}$ ) of the sperm suspension was transferred to a warm chamber (MUR-500; Matsunami, Osaka, Japan) and placed on a warm plate at $37^{\circ} \mathrm{C}$. The motility of the spermatozoa was immediately examined under a phase-contrast microscope. Sperm motility was expressed as a motility index calculated according to the method described by Okamura et al. (1985) with minor modifications:

$$
\text { Sperm motility index }=\frac{100 w+75 x+50 y+25 z}{100}
$$

where $w$ is the percentage of spermatozoa with rapid progressive motion (out of all spermatozoa in the assay mixture), $x$ is the percentage with slow progressive motion, $y$ is the percentage with rotational or non-progressive motion, and $z$ is the percentage with faint or pendulum-like motion. Assessments were made in three fields from one aliquot of each sample using a phase-contrast microscope $(\times 100$, Nikon TE300; Nikon, Tokyo, Japan).

Sperm viability was assessed using a live/dead stain combination (SYBR14/propidium iodide [PI], LIVE/DEAD Sperm Viability Kit; Molecular Probes, Inc., Eugene, OR, USA) according to the manufacturer's protocol with minor modifications (Blanco et al., 2000). Briefly, an aliquot of semen $(5 \mu \mathrm{L})$ was mixed with $50 \mu \mathrm{L}$ of a solution containing $3 \mu \mathrm{L}$ of PI (diluted 1:10 in distilled water) and $3 \mu \mathrm{L}$ of SYBR-14 (diluted 1:500 in DMSO) and incubated according 
to the manufacturer's instructions. One hundred spermatozoa were assessed in each of two duplicate aliquots of each sample and evaluated under a fluorescence microscope $(\times 200$, Nikon Eclipse 80 ; ; Nikon $)$ with a 488 -nm filter. The live sperm nuclei were stained by the SYBR-14 and fluoresced bright green, while the dead sperm nuclei exhibited red (PI) fluorescence.

The plasma membrane integrity of the sperm was assessed using the hypoosmotic swelling test (Ahmad et al., 2003). Briefly, an aliquot of semen $(20 \mu \mathrm{L})$ was mixed with $80 \mu \mathrm{L}$ of hypo-osmotic solution $(150 \mathrm{mOsm} / \mathrm{kg}$ ) containing $13.5 \mathrm{mg} / \mathrm{mL}$ D-fructose and $7.35 \mathrm{mg} / \mathrm{mL}$ trisodium citrate dehydrate in distilled water. The samples were incubated at $37^{\circ} \mathrm{C}$ for $10 \mathrm{~min}$, and then $10 \mu \mathrm{L}$ of each sample was placed on a slide and overlaid with a coverslip. One hundred spermatozoa in three fields from one aliquot of each sample were assessed using a phase-contrast microscope $(\times 400$, Nikon TE300; Nikon). The plasma membrane integrity of the sperm was expressed as the percentage of sperm with curled tails (intact plasma membrane) out of the total number of spermatozoa.

The acrosomal integrity of the spermatozoa was measured using fluorescein isothiocyanate-labelled peanut agglutinin (FITC-PNA; Vector Laboratories, Inc., Burlingame, CA, USA). The samples were spread on slides, air-dried at room temperature, and fixed with absolute ethanol for $10 \mathrm{~min}$ at room temperature. After drying, the slides were spread with $30 \mu \mathrm{L}$ of FITC-PNA $(100 \mu \mathrm{g} / \mathrm{mL})$ in PBS each and incubated in a dark, moist chamber for $30 \mathrm{~min}$ at $37^{\circ} \mathrm{C}$. The slides were then rinsed with PBS, air-dried, and overlaid with a coverslip. The acrosomal status (intact or reacted) was determined from the FITC-PNA staining pattern observed by fluorescence microscopy ( $\times 400$, Nikon Eclipse 80 i; Nikon) with a $488-n m$ filter. A total of 100 spermatozoa were counted over at least three different fields. The acrosomal integrity was expressed as the mean percentage of spermatozoa with intact acrosomes.

\section{Assessment of sperm penetrating ability and oocyte development}

after in vitro fertilisation

To examine the effect of skim-milk concentration on sperm penetrating ability after IVF, in vitro matured oocytes were co-incubated with boar sperm that had been preserved in Modified Modena extender with different concentrations $(0,7.5$ and $15 \mathrm{mg} / \mathrm{mL})$ of skim milk powder at $15^{\circ} \mathrm{C}$ for two weeks.

Porcine ovaries were obtained from a slaughterhouse and transported to the laboratory in $0.9 \%$ physiological saline at $30^{\circ} \mathrm{C}$ within $3 \mathrm{~h}$ of slaughter. $\mathrm{Cu}-$ mulus-oocyte complexes (COCs) were aspirated from follicles $3-6 \mathrm{~mm}$ in diameter and then collected into modified phosphate-buffered saline (m-PBS; Nihonzenyaku, Fukushima, Japan) supplemented with $100 \mathrm{IU} / \mathrm{mL}$ penicillin G potassium (Meiji) and $0.1 \mathrm{mg} / \mathrm{mL}$ streptomycin sulphate (Meiji). Groups of about 10 to 15 COCs were cultured for $22 \mathrm{~h}$ in a $100-\mu \mathrm{L}$ drop of in vitro maturation (IVM) medium consisting of tissue culture medium 199 (Earle's salts) buffered 
with 25 mM HEPES buffer (TCM 199; Invitrogen, Carlsbad, CA, USA), 10\% (v/v) porcine follicular fluid, $0.6 \mathrm{mM}$ cysteine (Sigma-Aldrich), $50 \mu \mathrm{M}$ sodium pyruvate (Sigma-Aldrich), $2 \mathrm{mg} / \mathrm{mL}$ D-sorbitol (Wako Pure Chemical Industries), $1 \mu \mathrm{g} / \mathrm{mL} 17 \beta$-oestradiol (Sigma-Aldrich), $50 \mu \mathrm{M} \beta$-mercaptoethanol (Wako Pure Chemical Industries), $10 \mathrm{IU} / \mathrm{mL}$ equine chorionic gonadotropin (KawasakiMitaka, Kawasaki, Japan), $10 \mathrm{IU} / \mathrm{mL}$ human chorionic gonadotropin (KawasakiMitaka), and $50 \mu \mathrm{g} / \mathrm{mL}$ gentamicin (Sigma-Aldrich). The COCs were then transferred to IVM medium without hormones and cultured for an additional $22 \mathrm{~h}$. All incubations were performed in a $38.5^{\circ} \mathrm{C}$ humidified incubator containing $5 \%$ $\mathrm{CO}_{2}$ in air.

In vitro fertilisation (IVF) of IVM oocytes was carried out according to the method described by Kikuchi et al. (2002) with minor modifications. The IVF medium contained $90 \mathrm{mM} \mathrm{NaCl}, 12 \mathrm{mM} \mathrm{KCl}, 25 \mathrm{mM} \mathrm{NaHCO}, 0.5 \mathrm{mM}$ $\mathrm{NaH}_{2} \mathrm{PO}_{4}, 0.5 \mathrm{mM} \mathrm{MgSO}$, $10 \mathrm{mM}$ sodium lactate (Sigma-Aldrich), $3 \mathrm{mg} / \mathrm{mL}$ bovine serum albumin (BSA; fatty acid free, Sigma-Aldrich), $5 \mathrm{mM}$ caffeine (Sigma-Aldrich) and $50 \mu \mathrm{g} / \mathrm{mL}$ gentamicin. After IVM, COCs were transferred into $100-\mu \mathrm{L}$ drops of IVF medium covered by mineral oil. About 15 oocytes per $100 \mu \mathrm{L}$ medium were fertilised by spermatozoa that had been preserved in Modified Modena extender with or without skim milk at $15{ }^{\circ} \mathrm{C}$ for 2 weeks. The final concentration of spermatozoa was $5 \times 10^{6} / \mathrm{mL}$. Oocytes and spermatozoa were co-incubated for $20 \mathrm{~h}$ in a $38.5{ }^{\circ} \mathrm{C}$ humidified incubator containing $5 \% \mathrm{CO}_{2}, 5 \%$ $\mathrm{O}_{2}$ and $90 \% \mathrm{~N}_{2}$. The inseminated oocytes were then denuded from the cumulus cells and attached spermatozoa by mechanical pipetting. As a fresh control, sperm were not preserved and were used for the evaluation of sperm penetrating ability and oocyte development after IVF.

After IVF, some of the presumptive denuded zygotes were mounted on glass slides, and fixed with a mixture of acetic acid and ethanol $(1: 3 \mathrm{v} / \mathrm{v})$ for 48 $72 \mathrm{~h}$. The fixed zygotes were stained with acetic-orcein (1\% orcein in $45 \%$ acetic acid) and examined under a phase-contrast microscope. Oocytes containing both female and male pronuclei were considered fertilised and were categorised as monospermic or polyspermic according to the numbers of swollen sperm heads and pronuclei in the cytoplasm.

The other denuded zygotes were transferred to $100 \mu \mathrm{L}$ droplets of PZM-5 (Research Institute for the Functional Peptides Co., Yamagata, Japan) and then cultured in vitro (IVC) at $38.5{ }^{\circ} \mathrm{C}$ in a humidified incubator containing $5 \% \mathrm{CO}_{2}$, $5 \% \mathrm{O}_{2}$ and $90 \% \mathrm{~N}_{2}$. At $72 \mathrm{~h}$ after insemination, all cleaved embryos were transferred into fresh PZM-5 with 5\% fetal bovine serum (Invitrogen), then cultured for an additional 5 days to evaluate their ability to develop to the blastocyst stage. All embryos were fixed on day 8 (day 0 ; insemination) and permeabilised for $15 \mathrm{~min}$ at room temperature in PBS containing 3.7\% (w/v) paraformaldehyde and $1 \%(\mathrm{v} / \mathrm{v})$ Triton X-100 (Sigma-Aldrich), and then placed in PBS containing $0.3 \%(\mathrm{w} / \mathrm{v})$ polyvinylpyrrolidone for $15 \mathrm{~min}$ at room temperature. Embryos were 
then placed in the drop of mounting medium on a slide. The mounting medium consisted of $90 \%(\mathrm{v} / \mathrm{v})$ glycerol containing $1.9 \mu \mathrm{M}$ Hoechst 33342 (SigmaAldrich). The embryos were examined under a fluorescence microscope with a $355 \mathrm{~nm}$ wavelength excitation filter. Embryos with a clear blastocoele and cells were defined as blastocysts.

\section{Statistical analysis}

All experiments were repeated four or five times. All data were subjected to arcsine transformation before analysis. Data were analysed by analysis of variance (ANOVA) using the program package SAS (SAS for Windows, version 9.1; SAS Institute Japan, Tokyo, Japan). Differences in probability values (P) of 0.05 or less were considered statistically significant.

\section{Results}

\section{Sperm quality}

The characteristics of boar sperm preserved in Modified Modena extender supplemented with different concentrations of skim milk are shown in Fig. 1. During four weeks of preservation, the supplementation of $7.5 \mathrm{mg} / \mathrm{mL}$ skim milk powder to Modified Modena extender increased the indices of sperm motility compared with the control group $(\mathrm{P}<0.05)$. The supplementation of $15 \mathrm{mg} / \mathrm{mL}$ skim milk powder also provided higher indices of sperm motility after two weeks of preservation when compared with the control group $(\mathrm{P}<0.05)$. However, skim-milk supplementation at a higher concentration $(50 \mathrm{mg} / \mathrm{mL})$ showed negative effects on sperm motility after two weeks of preservation (Fig. 1A).

The supplementation of $7.5 \mathrm{mg} / \mathrm{mL}$ skim milk powder was associated with higher rates of sperm viability after three weeks of preservation compared with the control group $(\mathrm{P}<0.05)$. However, reduced sperm viability was found in the highconcentration groups ( $\geq 30 \mathrm{mg} / \mathrm{mL}$ ) (Fig. 1B). The supplementation of skim milk did not improve the percentages of plasma membrane integrity and acrosomal integrity of preserved sperm compared with the control group (Figs 1C and 1D).

\section{Sperm penetrating ability and oocyte development after IVF}

The penetrating ability and oocyte development after IVF using sperm preserved in Modified Modena extender supplemented with different concentrations of skim milk at $15{ }^{\circ} \mathrm{C}$ for two weeks are shown in Table 1 . The total fertilisation rates of preserved sperm were significantly lower $(\mathrm{P}<0.05)$ than those of the fresh control sperm, regardless of skim milk supplementation. In the preserved sperm, the total fertilisation rate of sperm preserved with $7.5 \mathrm{mg} / \mathrm{mL}$ skim milk powder tended to be higher $(\mathrm{P}<0.1)$ than that of sperm with $15 \mathrm{mg} / \mathrm{mL}$ skim 

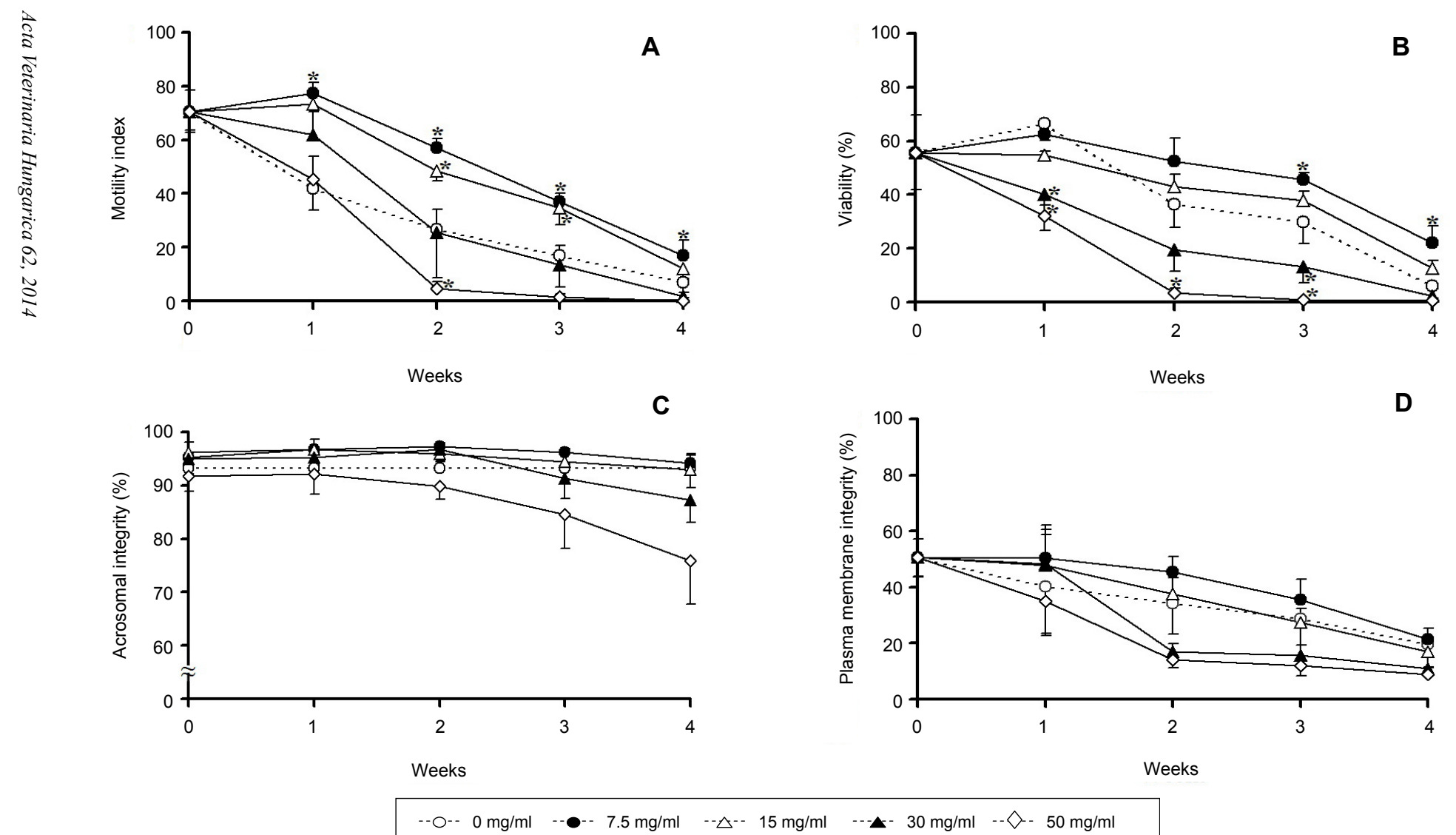

Fig. 1. Effects of skim-milk supplementation on motility (A), viability (B), acrosomal integrity (C) and plasma membrane integrity (D) of boar semen preserved at $15^{\circ} \mathrm{C}$ for 4 weeks. Boar semen preserved without skim milk served as control and 4 replicated trials were carried out. Asterisks $(*)$ indicate significant differences compared with the control $(0 \mathrm{mg} / \mathrm{mL})(\mathrm{P}<0.05)$ 
Table 1

Sperm penetrating ability and oocyte development after in vitro fertilisation using boar sperm preserved with various concentrations of skim milk at $15^{\circ} \mathrm{C}$ for two weeks ${ }^{*}$

\begin{tabular}{lccccc}
\hline \multirow{2}{*}{$\begin{array}{l}\text { Concentration } \\
\text { of skim milk } \\
(\mathrm{mg} / \mathrm{mL})^{* *}\end{array}$} & $\begin{array}{c}\text { No. } \\
\text { of oocytes examined }\end{array}$ & \multicolumn{2}{c}{ No. $(\%)$ of oocytes fertilised } & & \multicolumn{2}{c}{$\begin{array}{c}\text { No. } \\
\text { Monospermic } \\
\text { fertilisation }\end{array}$} & & $\begin{array}{c}\text { No. }(\%) \\
\text { of oocytes examined } \\
\text { of embryos that developed } \\
\text { to blastocysts }\end{array}$ \\
\hline Fresh control & 248 & $131(50.7 \pm 2.6)^{\mathrm{a}}$ & $47(32.7 \pm 3.8)^{\mathrm{a}}$ & 156 & $26(15.8 \pm 2.0)$ \\
0 & 109 & $33(30.0 \pm 3.8)^{\mathrm{b}}$ & $12(35.3 \pm 2.8)^{\mathrm{ab}}$ & 140 & $13(8.8 \pm 4.0)$ \\
7.5 & 111 & $43(38.9 \pm 1.8)^{\mathrm{b}}$ & $18(41.8 \pm 4.3)^{\mathrm{ab}}$ & 143 & $17(11.8 \pm 2.1)$ \\
15 & 107 & $28(26.0 \pm 3.0)^{\mathrm{b}}$ & $13(48.0 \pm 4.8)^{\mathrm{b}}$ & 135 & $15(10.4 \pm 3.4)$ \\
\hline
\end{tabular}

${ }^{*}$ Percentages are expressed as the mean \pm SEM. Four replicated trials were carried out. ${ }^{* *}$ Fresh control sperm were not preserved and were used for evaluation of sperm penetrating ability. ${ }^{* * *}$ The proportions of monospermic fertilisation were calculated by dividing the number of monospermic fertilised oocytes by the total number of fertilised oocytes. ${ }^{a}$ b $V a l u e s$ with different superscript letters in the same column differ significantly $(\mathrm{P}<$ $0.05)$ 
milk powder, but was not different from that of sperm preserved without skim milk powder $(0 \mathrm{mg} / \mathrm{mL})$. The monospermic fertilisation rate of sperm preserved with $15 \mathrm{mg} / \mathrm{mL}$ skim milk powder was higher $(\mathrm{P}<0.05)$ than that of fresh nonpreserved sperm, but did not differ among the preservation groups. There were no significant effects of skim-milk supplementation on the rates of development to blastocysts of oocytes after IVF using preserved sperm.

\section{Discussion}

Liquid preservation is still the preferred method for boar semen preservation. The present study demonstrated that skim milk is an effective additive for liquid preservation of boar semen at $15{ }^{\circ} \mathrm{C}$ for at least two weeks.

During liquid preservation, live sperm generally consume and metabolise oxygen, thereby producing the metabolite product ROS (Agarwal et al., 2003). The ROS may accumulate during the storage of semen in the absence of appropriate antioxidants in the semen extender. Once an imbalance between the production and removal of ROS occurs, the generation of excessive ROS subjects the spermatozoa to oxidative stress (Michael et al., 2008). In general, antioxidants prevent oxidant-mediated damage by free radicals or their reactive metabolites. They can reduce the impact of oxidative stress during the sperm preservation process and improve the quality of liquid-preserved sperm (Storey, 1997). Skim milk has been considered to be a non-enzymatic antioxidant that functions by the sulphhydryl groups (Bustamante Filho et al., 2009). In the present study, we found that the supplementation of 7.5 and $15 \mathrm{mg} / \mathrm{mL}$ skim milk powder to semen extender could improve the sperm motility up to four weeks of preservation. Moreover, supplementation of skim milk powder at $7.5 \mathrm{mg} / \mathrm{mL}$ contributed to positive effects on sperm viability. These results may indicate that skim milk may protect boar sperm from the generation of excess ROS, which is known to exert physical and chemical effects on sperm quality (Michael et al., 2008). On the other hand, our results revealed that supplementation with high concentrations of skim milk powder $(\geq 30 \mathrm{mg} / \mathrm{mL}$ ) had a negative effect on sperm quality parameters of boar semen preserved at $15{ }^{\circ} \mathrm{C}$. Relatively high concentrations of skim milk may cause hypertonicity of the extender, leading to an efflux of water from the cell and reduced motility and viability (Songsasen et al., 2002).

The most accurate indication of boar semen quality is viable pregnancies and offspring following AI, but this is not feasible as a routine method of sperm fertility assay (Bavister and Arlotto, 1990). Therefore, IVF seems to be the most informative method for assessing the penetrating ability of sperm (Xu et al., 1998). In the present study, we found that the supplementation of skim milk had no significant effects on the penetrating ability and development to blastocysts of oocytes after IVF using sperm preserved for two weeks, regardless of the con- 
centration of skim milk. During the first step of fertilisation, sperm must secrete their acrosomal contents (the 'acrosome reaction') to allow the sperm to penetrate the extracellular matrix of the oocyte and reach the oocyte plasma membrane at the site of fertilisation (Gadella and Evans, 2011). The hyper-activation of sperm is thought to be critical for the penetration through the zona pellucida of the oocyte (Suarez and Ho, 2003). Pommer et al. (2002) suggested that skim milk extender shortens the lifespan and maintenance of fertility of equine semen by induction of the acrosome reaction during incubation at $37^{\circ} \mathrm{C}$. However, we observed that in cool-preserved porcine semen, skim milk in the semen extender did not contribute to premature induction of the acrosome reaction, regardless of the preservation periods. In other words, skim-milk supplementation had no detrimental effects on the acrosome integrity of sperm during liquid preservation. Moreover, there were no significant differences in the percentages of acrosome integrity of preserved sperm between the skim-milk supplementation and control groups, and a higher acrosomal integrity of sperm in the control group was maintained even after 4 weeks of preservation. On the other hand, sperm penetration gives rise to cortical granule exocytosis following $\mathrm{Ca}^{2+}$ oscillations, resulting in the block of polyspermy (Kurokawa et al., 2004). In our study, the monospermic fertilisation rate of sperm preserved with $15 \mathrm{mg} / \mathrm{mL}$ skim milk powder increased when compared to fresh non-preserved sperm. However, the ratio of polyspermic and monospermic zygotes did not differ significantly between the skim-milk supplementation and control $(0 \mathrm{mg} / \mathrm{mL})$ groups, suggesting that the skim milk-based extender had no effect on the activity of the sperm responsible for cortical granule exocytosis in the oocyte. Therefore, a possible reason for no apparent effects of skim-milk supplementation on the penetrating ability and oocyte development after IVF could be the high acrosomal integrity maintained in the control group.

In summary, our results indicate that the supplementation of $7.5 \mathrm{mg} / \mathrm{mL}$ skim milk powder to semen extender improves sperm motility and viability after long-term preservation. However, the supplementation of skim milk had no apparent effects on the other parameters of sperm quality and sperm penetrating ability.

\section{Acknowledgements}

This study was supported in part by Grants-in-Aid for 'Research and Development Projects for Application in Promoting New Policy of Agriculture Forestry and Fisheries' from the Ministry of Agriculture, Forestry and Fisheries, Japan. The authors thank the staff of the Meat Inspection Office of the city of Kitakyushu, Japan, for supplying the pig ovaries. 


\section{References}

Agarwal, A., Saleh, R. A. and Bedaiwy, M. A. (2003): Role of reactive oxygen species in the pathophysiology of human reproduction. Fertil. Steril. 79, 829-843.

Ahmad, Z., Anzar, M., Shahab, M., Ahmad, N. and Andrabi, S. M. (2003): Sephadex and sephadex ion-exchange filtration improves the quality and freezability of low-grade buffalo semen ejaculates. Theriogenology 59, 1189-1202.

Bavister, B. D. and Arlotto, T. (1990): Influence of single amino acids on the development of hamster one-cell embryos in vitro. Mol. Reprod. Dev. 25, 45-51.

Blanco, J. M., Gee, G., Wildt, D. E. and Donoghue, A. M. (2000): Species variation in osmotic, cryoprotectant, and cooling rate tolerance in poultry, eagle, and peregrine falcon spermatozoa. Biol. Reprod. 63, 1164-1171.

Bustamante Filho, I. C., Pederzolli, C. D., Sgaravatti, A. M., Gregory, R. M., Dutra Filho, C. S., Jobim, M. I. M. and Mattos, R. C. (2009): Skim milk-egg yolk based semen extender compensates for nonenzymatic antioxidant activity loss during equine semen cryopreservation. Anim. Reprod. 6, 392-399.

Einarsson, S., Soosalu, O., Swenssou, T. and Viring, S. (1972): On the fertility and survival of deep frozen boar spermatozoa thawed in skim milk. Acta Vet. Scand. 13, 446-448.

Evelson, P., Travacio, M., Repetto, M., Escobar, J., Llesuy, S. and Lissi, E. A. (2001): Evaluation of total reactive antioxidant potential (TRAP) of tissue homogenates and their cytosols. Arch. Biochem. Biophys. 388, 261-266.

Gadella, B. M. and Evans, J. P. (2011): Membrane fusions during mammalian fertilization. Adv. Exp. Med. Biol. 713, 65-80.

Griveau, J. F., Dumont, E., Renard, P., Callegari, J. P. and Le Lannou, D. (1995): Reactive oxygen species, lipid peroxidation and enzymatic defence systems in human spermatozoa. J. Reprod. Fertil. 103, 17-26.

Johnson, L. A., Weitze, K. F., Fiser, P. and Maxwell, W. M. (2000): Storage of boar semen. Anim. Reprod. Sci. 62, 143-172.

Kikuchi, K., Onishi, A., Kashiwazaki, N., Iwamoto, M., Noguchi, J., Kaneko, H., Akita, T. and Nagai, T. (2002): Successful piglet production after transfer of blastocysts produced by a modified in vitro system. Biol. Reprod. 66, 1033-1041.

Kurokawa, M., Sato, K. and Fissore, R. A. (2004): Mammalian fertilization: from sperm factor to phospholipase Czeta. Biol. Cell 96, 37-45.

Michael, A. J., Alexopoulos, C., Pontiki, E. A., Hadjipavlou-Litina, D. J., Saratsis, P., Ververidis, H. N. and Boscos, C. M. (2008): Quality and reactive oxygen species of extended canine semen after vitamin $\mathrm{C}$ supplementation. Theriogenology 70, 827-835.

Okamura, N., Tajima, Y., Soejima, A., Masuda, H. and Sugita, Y. (1985): Sodium bicarbonate in seminal plasma stimulates the motility of mammalian spermatozoa through direct activation of adenylate cyclase. J. Biol. Chem. 260, 9699-9705.

Pagl, R., Aurich, J. E., Muller-Schlosser, F., Kankofer, M. and Aurich, C. (2006): Comparison of an extender containing defined milk protein fractions with a skim milk-based extender for storage of equine semen at 5 degrees C. Theriogenology 66, 1115-1122.

Pommer, A. C., Linfor, J. J. and Meyers, S. A. (2002): Capacitation and acrosomal exocytosis are enhanced by incubation of stallion spermatozoa in a commercial semen extender. Theriogenology 57, 1493-1501.

Songsasen, N., Yu, I., Murton, S., Paccamonti, D. L., Eilts, B. E., Godke, R. A. and Leibo, S. P. (2002): Osmotic sensitivity of canine spermatozoa. Cryobiology 44, 79-90.

Storey, B. T. (1997): Biochemistry of the induction and prevention of lipoperoxidative damage in human spermatozoa. Mol. Hum. Reprod. 3, 203-213.

Suarez, S. S. and Ho, H. C. (2003): Hyperactivation of mammalian sperm. Cell Mol. Biol. (Noisyle-grand) 49, 351-356.

Xu, X., Pommier, S., Arbov, T., Hutchings, B., Sotto, W. and Foxcroft, G. R. (1998): In vitro maturation and fertilization techniques for assessment of semen quality and boar fertility. J. Anim. Sci. 76, 3079-3089. 